\title{
Belphégor
}

Littérature populaire et culture médiatique

15-1| 2017

1936: les Jeux olympiques dans la presse internationale

\section{«Ah ! oui, décidément il y a quelque chose que nous ne comprenons pas en Allemagne » : les Jeux olympiques de Berlin vus par la presse francophone belge en août 1936}

\section{Paul Aron and Vanessa Gemis}

\section{OpenEdition}

\section{Journals}

Electronic version

URL: http://journals.openedition.org/belphegor/888

DOI: $10.4000 /$ belphegor.888

ISSN: 1499-7185

Publisher

LPCM

\section{Electronic reference}

Paul Aron and Vanessa Gemis, « «Ah! oui, décidément il y a quelque chose que nous ne comprenons pas en Allemagne » : les Jeux olympiques de Berlin vus par la presse francophone belge en août 1936 », Belphégor [Online], 15-1 | 2017, Online since 04 July 2017, connection on 01 May 2019. URL : http://journals.openedition.org/belphegor/888; DOI : 10.4000/belphegor.888

This text was automatically generated on 1 May 2019.

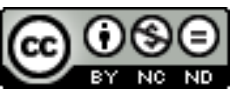

Belphégor est mis à disposition selon les termes de la Licence Creative Commons Attribution - Pas d'Utilisation Commerciale - Pas de Modification 4.0 International. 


\title{
«Ah! oui, décidément il y a quelque chose que nous ne comprenons pas en Allemagne » : les Jeux olympiques de Berlin vus par la presse francophone belge en août 1936
}

\author{
Paul Aron and Vanessa Gemis
}

\section{Méthodes et sources. État de la question}

Comment la presse belge francophone a-t-elle « vécu » les Jeux olympiques de 1936 ? $^{1}$ Qui sont les acteurs et quelles sont les orientations des médias écrits lors de ce grand événement sportif international, où sport, politique, nationalisme et morale entremêlent leurs enjeux ${ }^{2}$ ? Ces questions disent les limites de notre approche. Nous n'essayons pas de décrire l'attitude des autorités ou de l'opinion publique belge à propos des jeux : ceci a été fait ${ }^{3}$. Nous n'essayons pas non plus de rendre compte des techniques journalistiques mobilisées pour l'occasion : cela relève de l'histoire de la presse, que nous n'étudions pas. Mais entre l'histoire et le journalisme, il y a une place pour l'approche médiaticolittéraire que nous voulons illustrer à travers la question du reportage. Le reportage est, en soi, un genre pour partie littéraire. Il l'est par le statut de ses auteurs, souvent élevés au rang d'une élite de la profession journalistique qui a conquis son autonomie par la possibilité de monnayer sa signature. Il l'est aussi par le fait que de nombreux écrivains ont été amenés à faire du journalisme, et encore parce que les journalistes mobilisent des techniques d'expression dont l'organisation rhétorique est semblable à celle des genres littéraires reconnus. Il est donc permis de décrire le récit journalistique dans les termes d'une poétique, et, par conséquent, de tenter de voir si les textes publiés en la 
circonstance précise des JO confirment ou infléchissent ce que nous savons déjà de la poétique du grand reportage ${ }^{4}$.

Le corpus ${ }^{5}$ sur lequel nous avons travaillé se compose des principaux quotidiens belges francophones, ainsi que du seul quotidien sportif du temps (La Dernière Heure). Nous y avons joint un hebdomadaire (Cassandre) parce qu'il publie les articles d'un journaliste (Paul Werrie) qui travaille également pour la presse quotidienne. Nous avons par ailleurs dépouillé, sous la forme de coups de sonde, une série d'autres organes de presse, dont nous signalerons occasionnellement les contributions.

3 Si les grandes tendances de l'opinion publique sont représentées par ces journaux, on notera que manquent ici les quotidiens socialiste (Le Peuple) et communiste ( $L a$ Voix $d u$ peuple). Ces journaux ont strictement respecté la consigne internationale de boycott des Jeux, et ils se sont bornés à faire paraître quelques résultats sportifs, même si, assez étrangement, le journal socialiste a fait accréditer le journaliste Julien Monteyne pour suivre les compétitions. Cette abstention colore inévitablement tous les reportages: quelle que soit l'opinion du journaliste envoyé sur place, il aura accepté le principe même de sa présence aux Jeux!

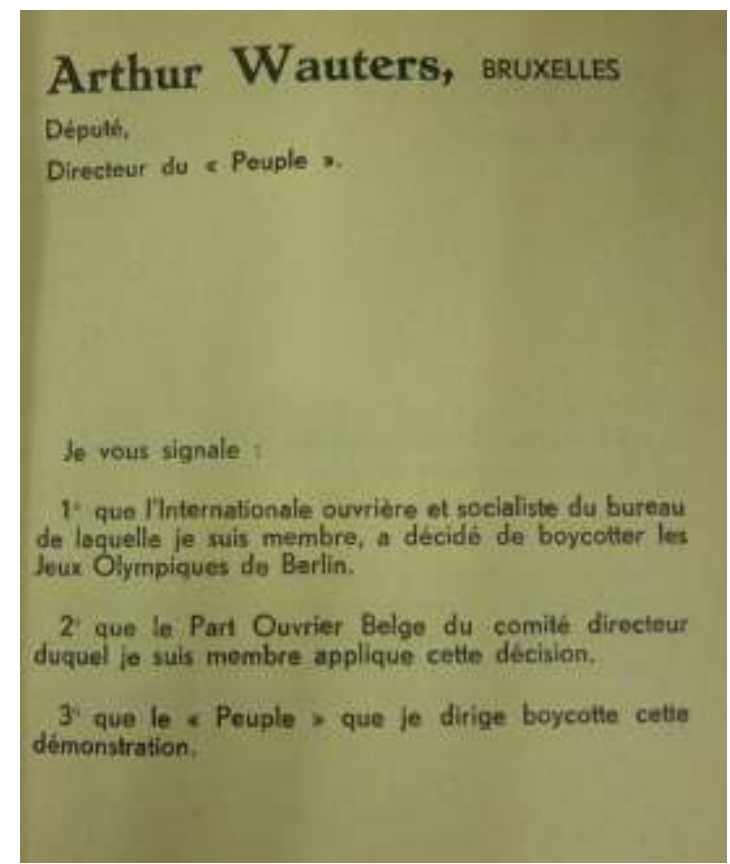

Contre les jeux olympiques de Berlin. Brochure publiée par le Comité international de défense de l'Idée olympique, Bruxelles, les Éditions continentales (3, av. Louise), 1936. Elle rassemble les avis négatifs d'un certain nombre d'intellectuels européens contre ces jeux.

Ce qui singularise les Jeux de 1936, tous les commentateurs l'ont observé, est une organisation matérielle particulièrement bien préparée. Celle-ci va de pair avec une série de choix idéologiques que l'on ne peut réduire à une simple propagande. Tout le volet symbolique des Jeux vise à installer une conception du monde cohérente où rien n'est laissé au hasard. En bonne méthode, il faudrait donc faire la liste des initiatives du régime nazi pour prendre la mesure du champ d'observation des journalistes : celles dont ils rendent compte, celles qu'ils ignorent, celles qui auront une pérennité dans l'histoire des Jeux, comme celles qui disparaitront après 1936. Plusieurs travaux historiques nous dispensent d'un inventaire trop détaillé6. Mais nous rappellerons les plus significatives, certaines étant parfois méconnues ou peu connues. 
Dès les premiers Jeux, le mouvement olympique - son nom même l'indique - fait référence à la Grèce antique. Mais nul pays organisateur, avant l'Allemagne, n'avait à ce point souligné ce lien. L'Allemagne nazie a financé des travaux archéologiques en Grèce bien avant 1936. La mythologie aryenne, nourrie par un certain nietzschéisme, s'est en partie forgée dans la construction d'un lien privilégié avec le classicisme grec. Ce lien est sensible à travers le site des JO, dans les stades et les théâtres dessinés par les architectes nazis ${ }^{7}$. Le théâtre d'Epidaure sert ainsi de modèle pour le Waldbühne ${ }^{8}$. De même, lorsque Albert Speer bâtit le stade olympique ${ }^{9}$, il prend modèle sur l'autel de Pergame qui a été reconstruit sur l'île des Musées de Berlin bien avant l'ère nazie.

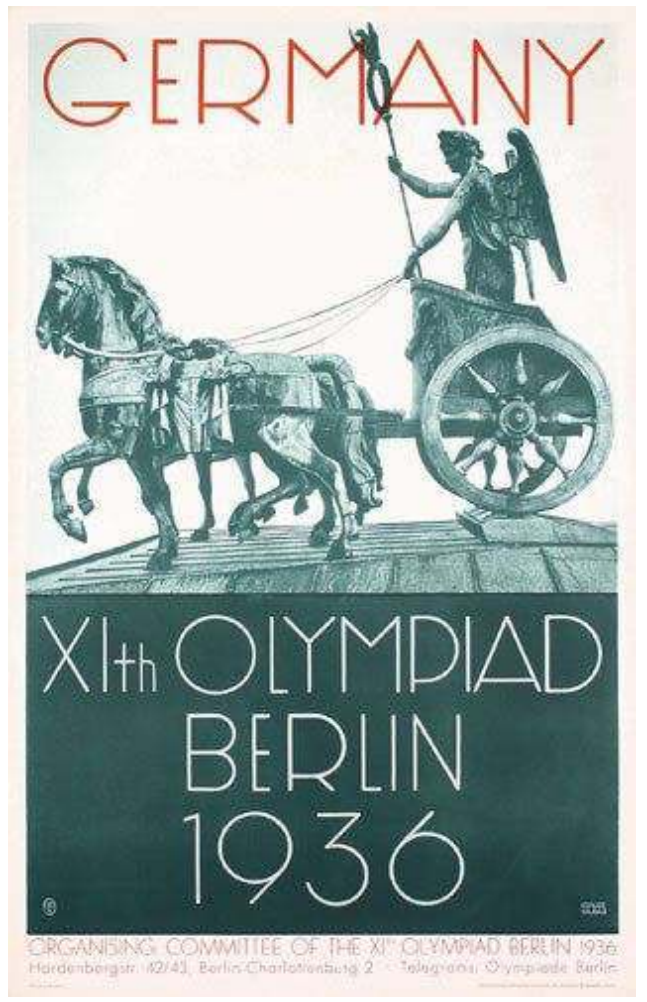

Version anglaise, source Pinterest.com

L'affiche des Jeux présente un aurige antique. Ce n'est pas un hasard si le film officiel des Jeux, confié à Leni Riefenstahl (1902-2003), qui avait été la cinéaste officielle des congrès du parti nazi depuis 1933 (Sieg des Glaubens, 1933 ; Triumph des Willens, 1934) s'ouvre par un ample fondu-enchaîné superposant Olympie et Berlin, le discobole avec le lanceur de disque allemand, et les statues des athlètes antiques avec leurs correspondants modernes. Pour matérialiser ce lien, les organisateurs des Jeux de Berlin inventent la symbolique de la flamme olympique: une torche allumée sur le site d'olympie qui parcourt les pays jusqu'à la cérémonie d'ouverture des Jeux. Il n'est pas sans intérêt de constater que le mouvement olympique a conservé ce symbole en n'assumant pas son origine : sur le site officiel du CIO, la flamme est célébrée, mais elle est présentée comme une invention d'après guerre! 


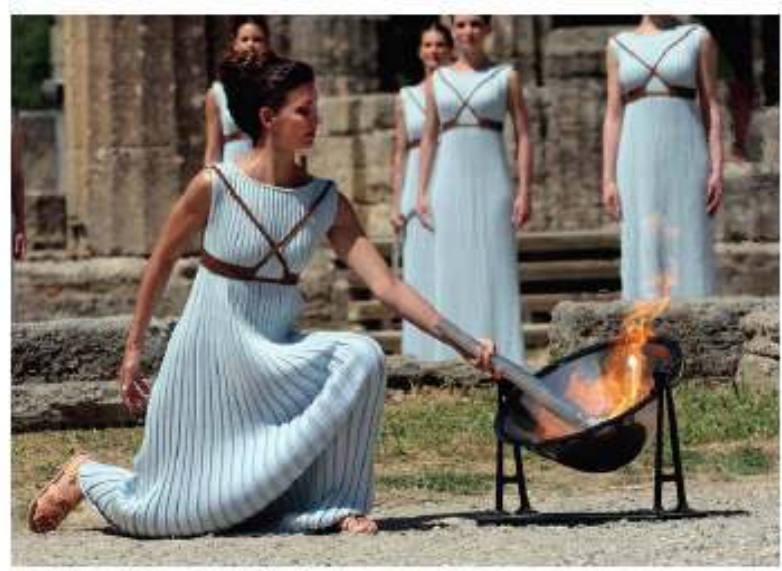

a aetry umaces

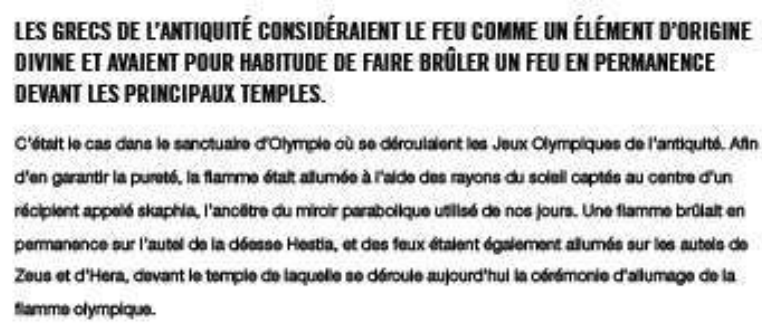

Site www.olympic.org/fr Héritage/Torches

7 L'importance donnée à la cérémonie d'ouverture, en présence du Führer et du président $\mathrm{du} \mathrm{CIO}$, contribue à installer un cadre non moins symbolique. Les drapeaux du régime y jouent le même rôle monumental que dans les grandes manifestations publiques du mouvement nazi mises en scène par Albert Speer. Ils forment une architecture animée rythmant l'espace et encadrant les masses humaines. Tous les spectateurs des Jeux participent, volontairement ou non, à ce spectacle: canalisés dès leur entrée dans le stade, disposés en groupes, ils donnent à la cérémonie la tonalité d'un défilé militaire, innombrable et discipliné.

8 La cérémonie de clôture n'est pas aussi simple à décoder. Dans le film de Leni Riefenstahl, elle apparait relativement discrète (tout est relatif), dans un décor de feux de projecteurs géométriques (ce sont des projecteurs de batteries antiaériennes). En parallèle, une seconde fête de clôture a lieu, qui n'apparaît pas dans le film. Son programme ne manque pas d'intérêt :

Werner Egk

Olympische Festmusik

Ballettmusik zum Festspiel «Olympische Jugend» (in einigen Quellen «Sieg der

Jugend »)

Orchestre :

Verstärktes Berliner Philharmonisches Orchester

Chef d'orchestre :

Werner Egk

Mise en scène :

Hanns Niedecken-Gebhardt

Chorégraphie :

Mary Wigman, Gret Palucca und Harald Kreutzberg

zusammen mit dem « Olympischen Reigen » von Carl Orff ${ }^{10}$ 
Il s'agit d'un spectacle chorégraphié par les principaux responsables de la danse moderniste allemande, avec deux partitions contemporaines, l'une de Werner Egk, l'autre de Carl Orff. Quelques photographies et films de répétition en portent témoignage, ainsi que des enregistrements sans doute postérieurs. Dans la mesure où la plupart de ces artistes ont survécu à la guerre et ont poursuivi leur carrière ensuite, on comprend aisément qu'ils n'aient pas voulu faire connaître leur contribution aux jeux olympiques. Mais cette cérémonie a sans doute déjà été occultée à l'époque, en raison des luttes de tendance entre "modernistes» et "traditionalistes» au sein du parti nazi. Une des raisons pour lesquelles le film de Riefenstahl n'est sorti en salles que deux ans après les Jeux tient très probablement à la progressive perte d'influence des créateurs les plus audacieux. Si cette question sort assurément du cadre sportif, il est cependant dommage que la plupart des envoyés de la presse belge aient passé sous silence la double cérémonie de clôture. Mais après tout, il est possible qu'ils n'aient pas été conviés au Festspiel ou qu'ils aient été rappelés par leur rédaction dès la fin des compétitions sportives stricto sensu.

Cette tension entre «modernité » et «tradition», tout comme la tension entre l'événement sportif et l'arrière-fond militaire, est perceptible à différents niveaux. L'architecture des monuments construits pour les Jeux est ainsi également symbolique par l'usage de certains matériaux. Le grand stade de Berlin est construit en béton armé, en raison des portées entre piliers, mais aussi de la rapidité de l'exécution, tout en étant recouvert d'un granit de façade, censé représenter une "pierre allemande " par sa solidité, et son usage traditionnel dans l'architecture des villes germaniques. Ses dimensions en font un bâtiment exceptionnel. Il inscrit par ailleurs dans un espace voué aux sports une série de références militaires significatives: sculptures, colonnes symétriques, espace de défilés et de parades. Sous une tribune du grand stade, la Langemarckhalle était censée rendre hommage à tous les morts de la Grande Guerre. Outre le fait que ce mélange entre une chapelle ardente et un monument aux morts surprend dans un bâtiment sportif, elle a manifestement été construite pour permettre des défilés militaires et des rencontres officielles. On ne sait si les sportifs belges y ont défilé, contrairement à d'autres délégations.

11 L'ouvrage officiel des Jeux n'est pas moins révélateur ${ }^{11}$. S'il n'a sans doute pas été largement distribué en raison de son poids et de son caractère monumental, ce livre témoigne de la fusion entre sport et milices armées. Il donne déjà la mesure du rôle de la SS dans l'organisation militaire nazie. Les photographies noir et blanc montrent des officiers qui s'entraînent au tir, des soldats faisant des exercices de gymnastique ou jouant des musiques militaires. A posteriori, ce document fait apparaître comme pusillanimes les hésitations rhétoriques de la presse sur les intentions du régime, comme celles du journaliste Georges Blun ${ }^{12}$. 


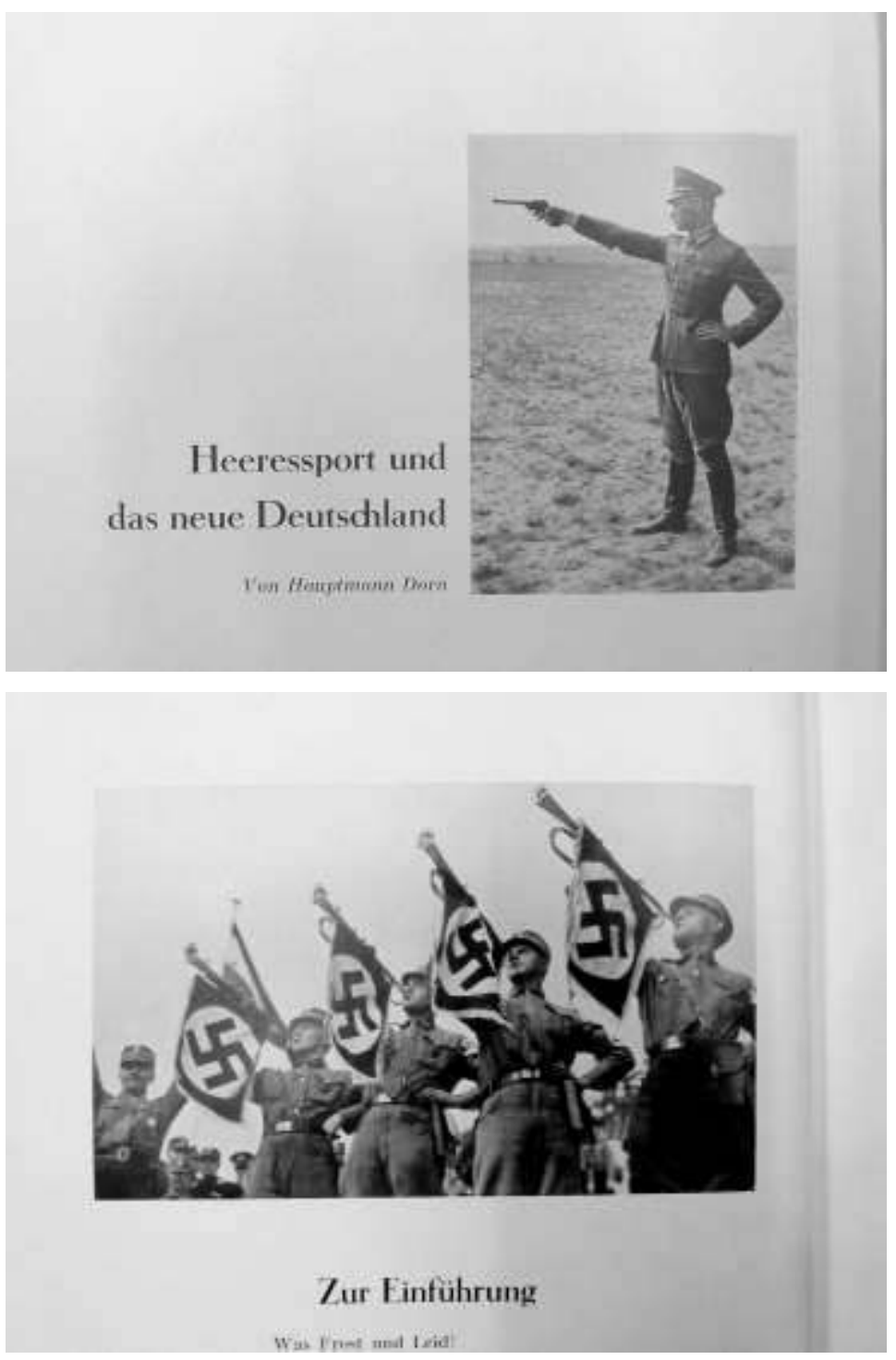

Comme on le sait, l'organisation des Jeux a suscité de nombreux débats. On peut résumer ceux-ci par les deux termes qui les ont condensés : la question du statut des athlètes juifs et la nature même du régime politique nazi. Le premier débat a principalement été porté par les organisations juives américaines. Le second est lié à la gauche européenne, qui a même envisagé d'organiser des Jeux parallèles à Barcelone. Si nous confrontons ces débats avec ce que nous savons aujourd'hui de la nature du régime nazi et les principales décisions antidémocratiques prises depuis 1933, on ne peut qu'être surpris par l'absence de toute référence dans la presse de l'époque au statut des Tsiganes, premières victimes en masse de la ségrégation raciale, pour lesquels se sont ouverts les premiers camps de concentration. Quant à l'opposition politique en Allemagne, qui concerne les communistes surtout, victimes de tortures, d'assassinats et d'internements arbitraires, elle ne sera jamais évoquée par la presse sportive belge pendant les Jeux.

Il faut enfin signaler ici les relations spécifiques de la Belgique aux Jeux. Les Olympiades de 1920, les premières organisées après la Grande Guerre, ont été présentées à Anvers. Dès ce moment, les Belges ont bénéficié d'une présence particulière dans le $\mathrm{CIO}$, en tant que pays particulièrement engagé dans le mouvement olympique, et également en tant que petite nation bénéficiant de sa quasi-neutralité dans le concert des grands états 
impliqués. Élu président du CIO en 1925, le comte de Baillet-Latour a eu un rôle déterminant dans le maintien des Jeux en Allemagne après l'accession d'Hitler au pouvoir. Il est l'un des principaux responsables de l'idéologie affichée par le Comité olympique organisant un événement purement sportif, à l'abri des considérations politiques de tous ordres ${ }^{13}$. L'assurance que nul athlète ne serait exclu des Jeux en fonction de sa race, et l'absence de discours inaugural de la part des autorités allemandes ont été les seules garanties exigées et obtenues auprès du régime hitlérien. La sympathie affichée par certaines hautes autorités belges pour ce régime, notamment de la part de l'ambassade de Belgique à Berlin, a de surcroît facilité le travail du comte. Pour autant, le gouvernement belge de l'époque, qui associait libéraux, catholiques et socialistes, s'est montré prudent. La délégation belge n'a pas été soutenue par les autorités politiques du pays, mais par le seul comité olympique national.

Les enjeux des Jeux permettent donc de définir un cadre de référence. On peut dès lors inscrire les « choses vues » des journalistes dans leur contexte, de manière à apprécier ce qu'ils ont voulu mettre en évidence comme ce qu'ils ont occulté.

\section{Grands et petits reporters}

La presse belge n'a pas fait appel à de "grandes plumes » d'exception pour couvrir les Jeux. Vingt-cinq journalistes ont été accrédités par les autorités allemandes, pour la presse francophone, flamande et germanophone belge ${ }^{14}$. Nous pouvons identifier trois journalistes importants, dont deux ont eu une carrière dépassant les cercles sportifs.

- L'envoyé spécial de La Nation belge est Gérard de Lantsheere, qui deviendra correspondant à Paris du journal et critique de cinéma. Il ne semble pas avoir laissé d'œuvre littéraire ${ }^{15}$.

- Paul Werrie (1901-1974), envoyé par Cassandre et Le Vingtième siècle, est un journaliste d'origine modeste (son père était boucher charcutier) et de confession catholique. Après un diplôme de candidat en philologie classique à l'Université Catholique de Louvain, Werrie mène une brillante carrière de chroniqueur sportif, mais également de critique cinématographique et théâtral pour Le Vingtième Siècle ; cofondateur du Journal des Poètes, il sera une des meilleures plumes du Nouveau journal (1940-1944), le quotidien dirigé par Robert Poulet sous l'Occupation. Il a été membre de La Libre Académie en 1935. Après la guerre, il quitte la Belgique pour l'Espagne, puis la France. On lui doit des ouvrages critiques (Le Théâtre de la fuite, 1943, sur la vie théâtrale en Belgique), et plusieurs romans où il évoque notamment son exil en Espagne et l'atmosphère de suspicion qui entoure les anciens collaborateurs (La Souille, 1972 ; Les Chiens d'aveugles, 1972 ; Condamnés à vivre, 1973.)

- Pierre Gosset (1911-1982) est un journaliste français indépendant en poste à Bruxelles. Dès 1933, il est mentionné dans l'Annuaire de la presse sportive belge comme "membre adhérent " à l'Association Professionnelle Belge des Journalistes Sportifs. En 1936, il est qualifié de «membre professionnel» de l'association ${ }^{16}$. Il écrit pour de nombreux périodiques sportifs (français ou belges) comme La Vie Sportive, Les Sports illustrés, Sporting, Le Sportman, L'Auto. Chef de la rubrique sportive du quotidien L'Indépendance Belge, il y exerce sa fonction de journaliste sportif de 1931 à 1937. C'est pour ce journal qu'il part à Berlin couvrir les Jeux olympiques en tant qu' «envoyé spécial »; son reportage y paraît du 31 juillet 1936 au 28 août 1936. Il fera ensuite carrière au Petit Parisien, et, avec son épouse Renée, participera à la revue illustrée Regards à laquelle le couple donnera de très nombreuses enquêtes menées dans le monde entier. 

aussi des articles de "notre correspondant particulier », Georges Blun. Le Matin d'Anvers publie les correspondances de plusieurs journalistes qui signent de leurs initiales : Frits Ardouillie (FA); Henry Narbot (HN); EFFA (qui n'est peut-être que Frits Ardouillie), Marcel Charlier (Ch.) et publie en outre des articles de fond d'un certain Armand Berlin. Ces personnes ne semblent pas avoir eu une autre activité que journalistique, et seul Ardouillie figure dans la liste des accrédités.

Certains correspondants enfin, et ils sont les plus nombreux, n'ont signé que de leurs initiales, ce qui était une tradition dans la presse avant que n'apparaissent des signatures vedettes ou des collaborateurs extérieurs. Pour La Libre Belgique, nous enregistrons d'abord un certain W.D., un premier journaliste très réservé sur la dimension de propagande. Lui succédera F.A. (sans doute Ardouillie), qui semble s'intéresser surtout aux résultats sportifs et occulte la politisation des jeux. La Métropole, d'Anvers, publie quelques reportages "de nos envoyés spéciaux ». Leur style suggère effectivement une écriture à plusieurs mains davantage que le témoignage d'un seul journaliste. Pourtant tous les articles sont signés des mêmes initiales : A. J. (Aloïs Janssens). Le reporter du Soir, qui signe «V. » ou une ou deux fois «Vidi. » n'a pas pu être identifié. La Meuse envoie «V. de C. », La Dernière Heure plusieurs reporters différents, « G. » pour commencer puis «D. » (Norbert Diagre), tandis que La Vie sportive confie ses reportages à « Spectateur » et à un nommé « R. Liégeois », que nous n'identifions pas plus précisément. Enfin, La Gazette de Charleroi fait appel à l'entraîneur de l'équipe belge de boxe Robert Bocqué pour rédiger six articles.

Comme l'indique le relatif anonymat qui entoure la plupart d'entre eux, les reporters belges sont donc loin d'être des vedettes. Ils sont également attachés le plus souvent à un ou deux journaux de la même obédience politique, et ils ne bénéficient pas de l'autonomie des grandes signatures de la presse française. Cette situation conditionne certainement leurs reportages sur le plan matériel. La plupart abrègent leur séjour à Berlin parce que le journal qui les emploie ne voit pas l'intérêt de dépenser de l'argent dès lors qu'aucun Belge ne figure parmi les vainqueurs. Ces journalistes n'ont pas l'autonomie qui leur aurait permis de sortir de la capitale allemande ou de mener une véritable enquête. Il nous faudra revenir ultérieurement sur ces faits pour en mesurer les conséquences sur la poétique de leurs reportages.

\section{Images des Jeux}

19 Du reste, les Jeux olympiques n'occupent dans la presse belge qu'une partie de l'espace éditorial. S'intéresser à la poétique même du support médiatique ${ }^{17}$ permet ainsi d'intégrer le texte dans son contexte d'édition, et d'éviter les écueils d'une lecture plus littéraire que médiatique du reportage. Ce « 'texte second' dont le signifiant n'est pas constitué par les mots de la langue, mais par la matérialité du support [...] constitue et réalise le 'texte premier', il lui permet d'exister. [...] La fonction du 'texte second' consiste à donner à lire le 'texte premier', sa signification (la connotation) nous renvoie à l'idéologie littéraire et textuelle d'une époque donnée. ${ }^{18}$ "

Si seule la presse de gauche jouera la carte complète du boycott, les journaux analysés témoignent en effet d'un intérêt extrêmement variable, allant du simple énoncé de résultats sportifs parfois accompagnés de dépêches d'agence ${ }^{19}$, à la publication régulière 
d'articles de natures diverses (reportages, articles de fond, résultats sportifs, agenda des compétitions, etc.). Une telle disparité peut d'abord s'expliquer par les moyens économiques propres à chaque journal, lesquels permettent ou non d'envoyer des reporters enquêter à l'étranger. On notera à ce titre la stratégie de La Gazette de Charleroi qui, n'ayant visiblement pas les moyens d'envoyer un journaliste à Berlin, publie néanmoins une série de reportages signés par l'entraîneur belge de l'équipe de boxe, Robert Bocqué. En plus de bénéficier du crédit accordé au spécialiste, à l'homme de terrain, Bocqué est entièrement financé par la Fédération sportive. Sur les six articles qu'il publie dans le journal, quatre portent sur le camp d'entraînement de Tilff, situé dans la région de Liège, et deux sur les compétitions berlinoises. Ce reportage qui couvre toute la période des Jeux olympiques offre donc au lecteur de La Gazette une vision originale de l'événement, et ce malgré l'absence d'un véritable grand reportage.

21 À une plus large échelle, les articles s'inscrivent également sur un support qui, comme le souligne Marie-Ève Thérenty, se caractérise par sa polyphonie ${ }^{20}$. Par la diversité tant de ses voix/signatures que des sujets traités, le journal s'impose comme un objet pluriel, dont l'ensemble influence la lecture des parties qui le composent. S'intéresser à la place des reportages consacrés aux JO dans l'économie générale du journal permet ainsi de penser ces derniers comme partie prenante d'une politique éditoriale et, plus largement, de réfléchir à la manière dont l'actualité a été donnée à lire aux lecteurs de l'époque. Autrement dit, de remettre en perspective la portée historique de l'événement. L'année 1936 est en effet marquée par une actualité lourde et la presse se montre davantage tournée vers la guerre civile en Espagne que vers les compétitions olympiques. 

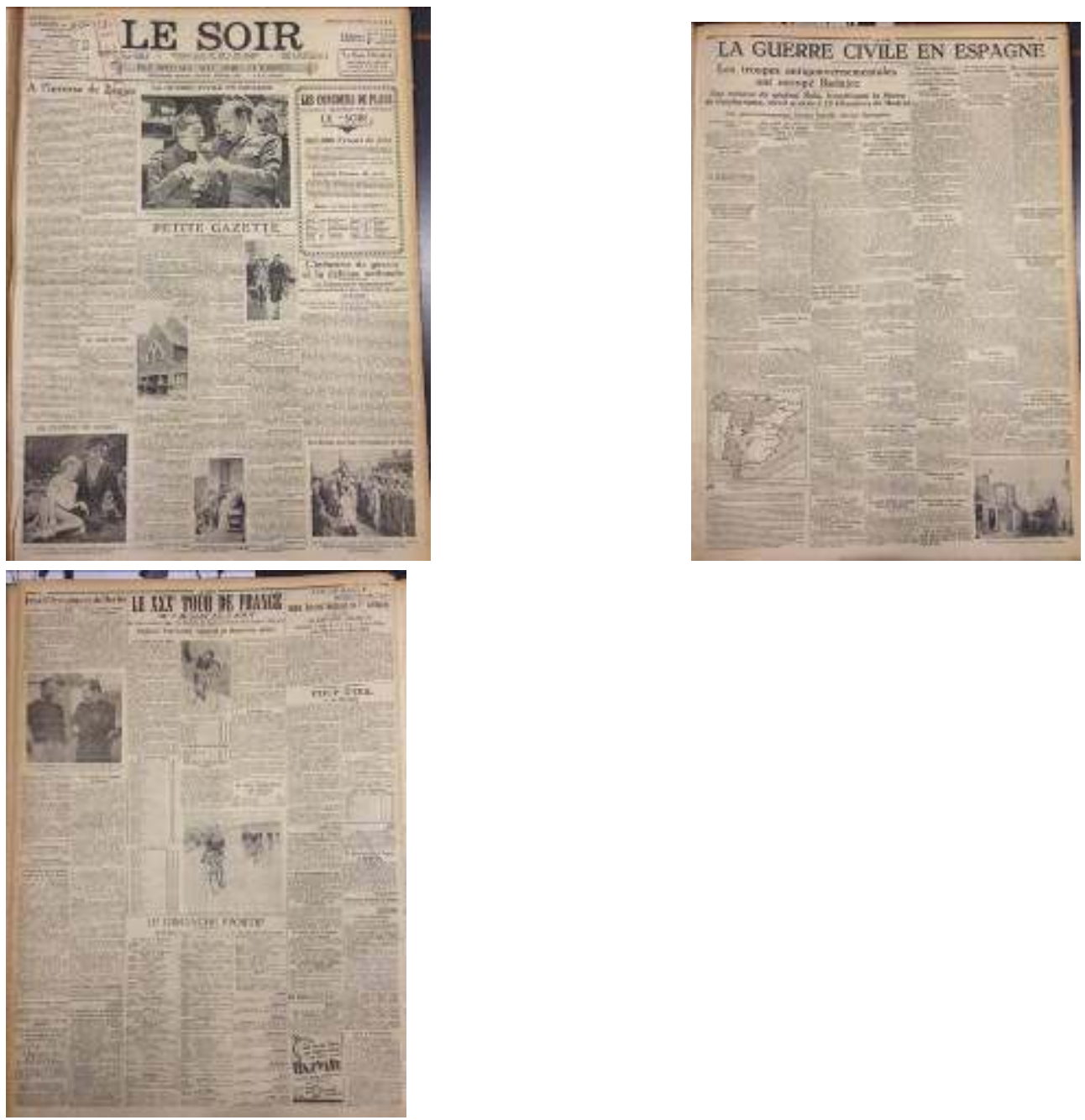

Le Soir, le 2 août 1936 - Les Jeux olympiques (3e planche - les deux colonnes de gauche) occupent une place largement inférieure à la Guerre civile en Espagne ( $2^{\mathrm{e}}$ planche - la pleine page)

Une brève comparaison entre le traitement médiatique des JO et de la Guerre d'Espagne dans des journaux comme La Meuse ou comme Le Vingtième siècle est significative. C'est en effet la guerre d'Espagne qui domine les titres et se trouve à la Une du premier quotidien, alors que plus de $60 \%$ des articles consacrés aux Jeux olympiques se trouvent en quatrième et cinquième pages, soit dans la rubrique sportive. Cet «effet-rubrique » a incontestablement un impact sur le mode de lecture de l'événement, mais indique sans doute aussi les lignes éditoriales auxquelles ont été soumis les reporters, invités ou non à relever la dimension politique de l'événement. Quant au Vingtième siècle, s'il consacre presque autant de colonnes au conflit en Espagne qu'aux JO (133 colonnes/128 colonnes), ces derniers ont tôt fait d'être relégués dans les pages intérieures de ses éditions, voire dans sa rubrique sportive, pour ne laisser à la Une que ses publications relatives à l'Espagne. Le cas d'un journal comme Le Matin semble donc plutôt atypique. Les Jeux olympiques y occupent une place importante, voire proportionnelle et équivalente à celle de la Guerre civile espagnole. Le journal n'a d'ailleurs pas hésité à diligenter à Berlin toute une équipe d'envoyés spéciaux. Mais sans doute faut-il rappeler ici qu'étant implanté à Anvers, Le Matin s'inscrit dans un paysage socio-économique d'emblée tourné vers l'Allemagne. Le port d'Anvers est à l'époque le deuxième port européen et l'un des 
principaux ports mondiaux, et entretient à ce titre de nombreuses et fructueuses relations avec l'Allemagne ${ }^{21}$.

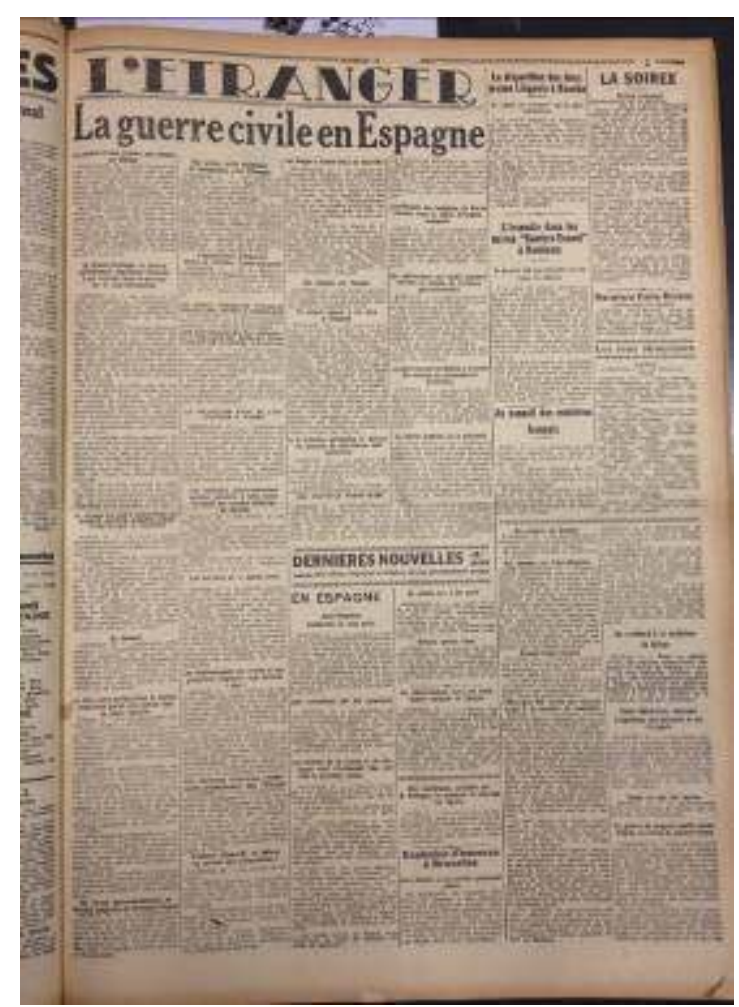

Le Matin, le 14 août 1936.

L'image des Jeux que véhicule le support médiatique dans son ensemble est tout naturellement portée également par les photographies. Celles-ci interviennent pour illustrer ou accompagner l'article, mais parfois aussi en lieu et place de ce dernier. Il est ainsi fréquent de voir une photo légendée relative aux JO en première page, alors que le reportage en lui-même ne se retrouve qu'en page 3 ou 4 du journal. Ces différents usages du matériau photographique suggèrent plusieurs rythmes de lecture : la photo exprimant avant le texte le propos de ce dernier; le texte venant expliciter la photo perçue en première instance ; la légende focalisant l'attention sur un élément clé du récit ; etc. Mais la photographie participe également de la poétique du support dans son ensemble, offrant des effets visuels (symétrie, mouvement, jeux d'ombres, etc.) qui ont autant pour effet d'attirer le lecteur vers un texte précis que de participer à l'esthétique d'ensemble du journal. Premier quotidien belge illustré, La Meuse en a d'ailleurs fait sa caractéristique et son fonds de commerce, créant son propre atelier de photogravure (l'agence Pim) qui travaillera en collaboration avec le studio parisien Keystone ${ }^{22}$. 


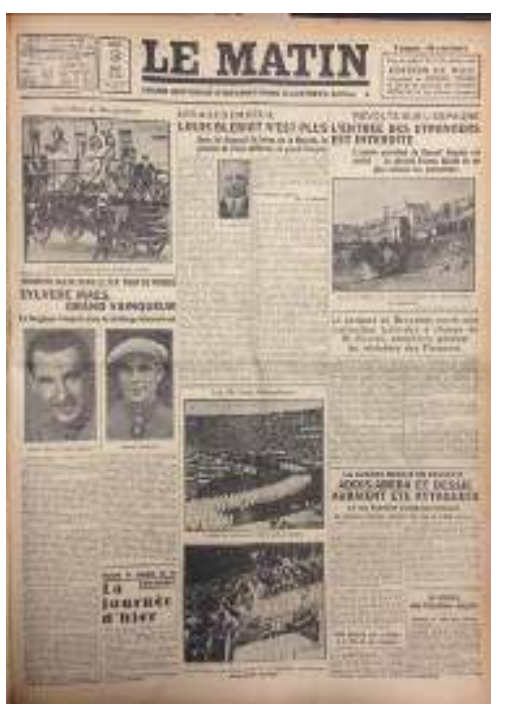

Le Matin, le 3 août 1936.

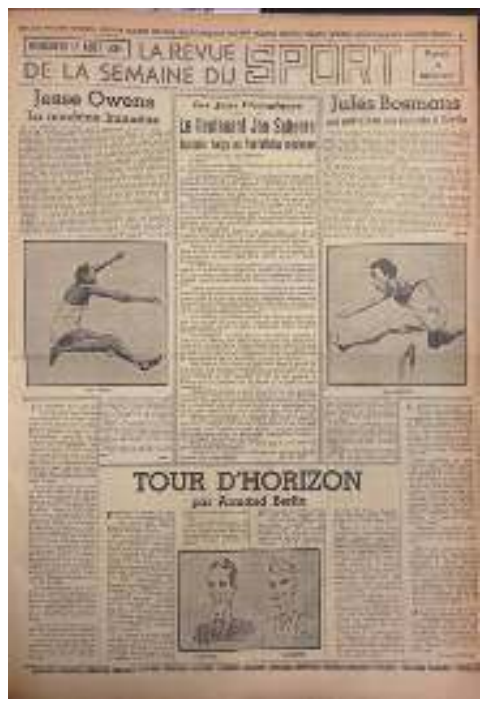

Le Matin, le 5 août 1936.

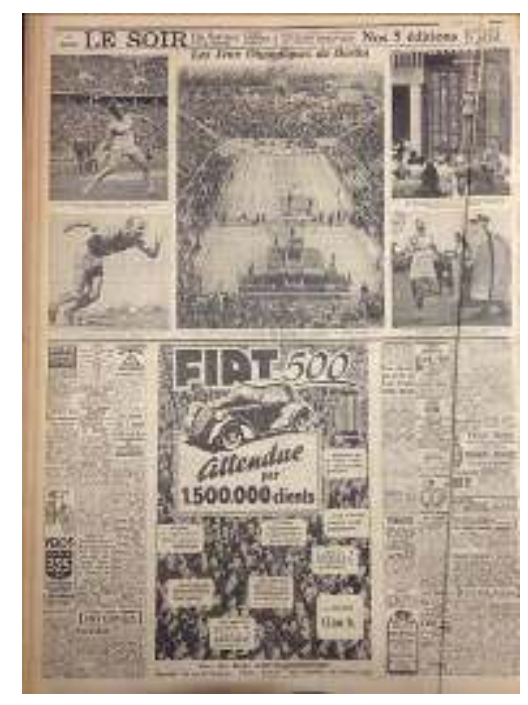

Le Matin, le 12 août 1936. 
Le cas des JO de Berlin permet toutefois d'interroger plus précisément les liens entre images et texte sportif. Les photographies peuvent occuper une large part de la surface éditoriale, imposant une dynamique bien plus qu'illustrative. Les photographies qui accompagnent des résultats sportifs viennent ainsi directement compenser l'absence de littérarité pour prendre en charge la narration. Cette mise en récit de l'événement passe alors par une esthétique visuelle mettant l'accent sur le mouvement, la vitesse, la corporalité, etc.

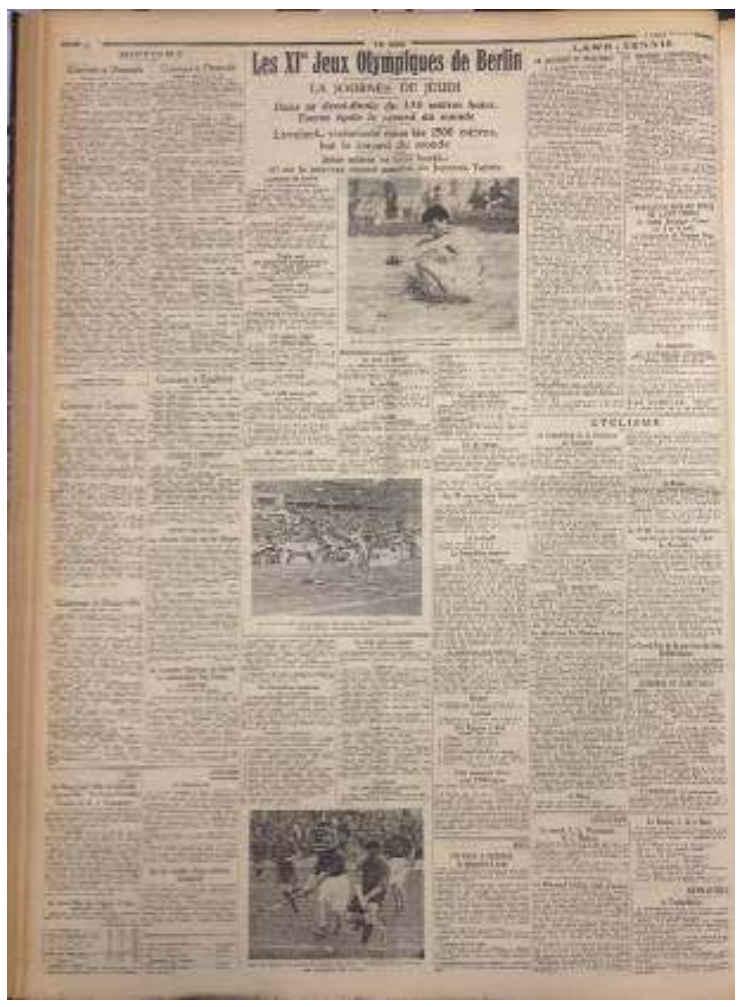

Le Soir, le 8 août 1936 - Résultats sportifs

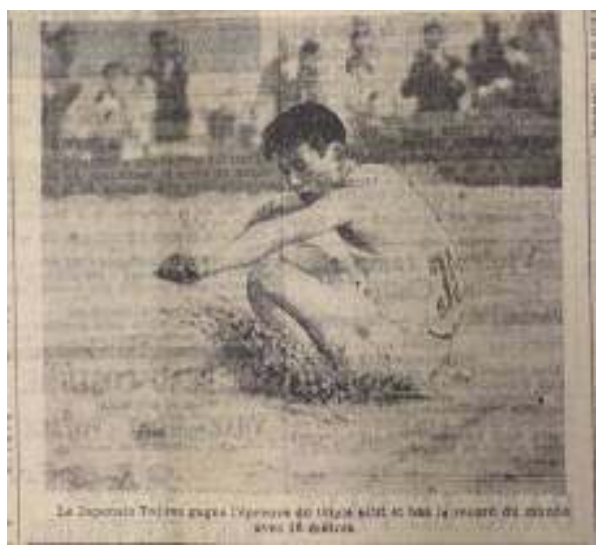

Idem

Il faut évidemment souligner que cette mise en images des Jeux participe pleinement des stratégies de la mise en scène allemande. La répétition de clichés identiques à travers différents organes laisse supposer que peu de journaux ont pu prendre leurs propres photographies et que ces dernières étaient sélectionnées et diffusées par les agences de presse allemandes. Les conditions d'écriture même des reportages sont largement cadrées 
par les autorités locales. Organisés par le ministère de la propagande, les JO sont pensés comme une vitrine de l'Allemagne. L'envoyé spécial de La Métropole souligne ainsi l'affabilité des autorités à l'égard des journalistes :

«La presse surtout est l'objet de toute la sollicitude des autorités allemandes. Non moins de 1200 journalistes, venant des quatre coins du monde, sont dûment accrédités pour suivre les Jeux. [...] Et partout, chez tout le monde, une affabilité, une serviabilité à toute épreuve, à tel point qu'on en devient tout étourdi et qu'on se demande vraiment si ces gens sont des hommes comme nous, s'ils peuvent se mettre en colère, être impolis, impatients, exigeants comme nous, mortels ordinaires... $»^{23}$

« Nous avons pu le constater déjà à de nombreuses reprises et en d'autres endroits que Berlin : l'Allemand est très accueillant et extrêmement poli. À l'occasion de l'Olympiade on a cependant renforcé la dose. La raison en est simple : comme le D

${ }^{\mathrm{r}}$ Goebbels l'a dit lui-même dans un discours aux représentants de la presse, il est de toute évidence que l'Allemagne veut se montrer à ses visiteurs étrangers, sous son meilleur aspect, dans sa robe de dimanche. On a tant dit et écrit sur l'Allemagne contemporaine, que l'Allemagne a tenu fort naturellement à profiter de l'occasion offerte par les Jeux olympiques, qui ne l'oublions pas, lui furent attribués dès 1932, pour montrer au monde qu'elle n'est pas le pays d'épouvante que certains rapports ont souvent évoqué. L'Allemagne d'Hitler a fait ici un effort gigantesque. [...] $»^{24}$ [Nous soulignons]

Le reporter ne semble donc pas dupe des efforts propagandistes sous-jacents. Par profession attentif à la scénographie, que son écriture va traduire, il ne peut en effet rester indifférent à un spectacle dont il est partie prenante, objet autant que sujet. Reste à savoir précisément si, de par leur statut de témoin, les reporters seront en mesure de décoder les enjeux des événements auxquels ils assistent et quels seront les procédés discursifs mis en œuvre pour transmettre aux lecteurs leurs expériences.

\section{Écrire les jeux}

Relevant d'abord d'une pratique professionnelle - celle du journalisme de terrain, le reportage se définit également comme une pratique d'écriture spécifique que l'on peut situer à mi-chemin entre presse et littérature. Le reportage met en effet au centre du journal un sujet voyant, un je dont le corps s'inscrit au cœur même du récit journalistique. La subjectivité qui sous-tend le récit garantit aux lecteurs l'authenticité des faits rapportés (procédé de littérarité propre à «la chose vue») mais légitime également une construction narrative et des effets de style propres à la littérature (procédé de littérarisation) qui garantissent au reporter son statut d'auteur et au reportage son statut de récit attractif. Envoyé spécial pour L'Indépendance belge, Pierre Gosset n'hésite pas à littérariser son discours en mettant en scène les sportifs, les officiels ou encore lui-même. Voici un exemple où il se compare à un sportif et qui illustre bien l'aspect littéraire de son reportage :

«Votre serviteur est très près d'établir aujourd'hui une performance olympique de premier ordre: celle du plus long parcours couvert par un journaliste au cours d'une journée des Jeux... Les kilomètres se sont déjà ajoutés ce matin aux kilomètres, et l'après-midi ne lui réserve que de nouvelles occasions d'améliorer sa performance. Sous un aspect de concentration, les installations olympiques sont étonnamment dispersées et les pelouses s'ajoutent aux bosquets, les allées aux escaliers, pour contribuer à allonger une distance qui, à vol d'oiseau, apparaît comme ridiculeusement anodine. Très heureux encore lorsqu'une excursion supplémentaire au village olympique ne lui inflige pas une heure et demie 
supplémentaire passée dans un autobus calamiteux, dont les propriétés propulsives deviennent nulles au-delà de l'allure vertigineuse de quarante kilomètres à l'heure... $»^{25}$ cérémonie d'ouverture des jeux. Celle-ci est traitée avec un soin particulier par l'envoyé spécial de La Vie Sportive :

"Une sonnerie de trompettes thébaines et, léger comme un sylphe, souple comme une danseuse, l'éphèbe descend l'escalier à toute allure, vole littéralement sur la piste, gravit sans effort apparent l'escalier de la porte de Marathon, s'arrête à côté de la vasque où brûlera tantôt la flamme olympique où, se détachant seul sur le ciel, il élève des deux mains le flambeau dans une pose hiératique, puis il plonge le flambeau dans la vasque d'où jaillit aussitôt la flamme qui ne s'éteindra qu'à la fin des jeux, tandis que les choristes et l'orchestre, sous la direction du fameux cappelmeister Johann Strauss, entonne l'Alleluia de la $9^{\mathrm{e}}$ Symphonie. Ce fut une inoubliable minute de beauté grecque. $»^{26}$

Sans aucune distance critique, le reporter adopte spontanément un lexique hellénisant qui mime les effets idéologiques souhaités par les concepteurs de l'événement. Sous sa plume, la cérémonie d'ouverture n'est guère présentée différemment que par la cinéaste allemande Leni Rieffenstahl!

La même cérémonie relatée par le reporter Paul Werrie, envoyé à Berlin par l'hebdomadaire Cassandre et le quotidien Le Vingtième Siècle, offre un tout autre spectacle au lecteur. L'article, publié dans Le Vingtième siècle le 17 août 1936, sous le titre «Un étrange spectacle à Berlin. 'Heilige flamme!' s'écria M. Goebbels ${ }^{27}$ mérite qu'on s'y attarde plus longuement.

Dès l'incipit, Werrie active le pacte référentiel par une écriture à la première personne qui garantit son statut de témoin. D'emblée il souligne aussi qu'il s'agit de comprendre et donner « sens... aux Jeux de Berlin » :

"Je vous envoie ici, après coup (mais on est ici débordé, submergé, par le flot des images qui déferlent sur nous, qu'il faut enregistrer, avant de pouvoir les développer, comme des films), la relation de la cérémonie à laquelle j'ai assisté le samedi matin, jour de l'ouverture des Jeux.

La question d'actualité ne joue guère. D'abord, nous avons vu très peu de journalistes à la tribune qui leur était réservée, et très peu de Français, dans tous les cas. Tout comme à la Fête du Soir, "Jeunesse Olympique", que nous vous narrerons plus tard, car on ne peut tout faire à la fois. On le répète, la question de date ne peut intervenir.

La cérémonie dont nous parlons ci-dessous revêt une importance primordiale quant aux sens qu'il faudra définitivement accorder aux Jeux de Berlin.» [nous soulignons]

Le style adressé («vous») participe également pleinement de la poétique d'un genre journalistique qui ambitionne une lecture participative. Le récit d'enquête ne cherche plus à «faire croire », par quelque « effet de réel », mais, plus performativement, à « faire voir » (« images », « assisté », «vu»). A l'illusion réaliste » il substitue « une illusion du direct » dont les procédés narratifs relèvent tant de l'usage des temps (le présent, voire le passé composé) et d'une scénarisation graduelle que d'une recherche stylistique relevant de l'hypotypose. Le reporter entend faire ressentir au lecteur l'ambiance à la fois sonore et visuelle de la ville. "Berlin est une ville de rythme » écrit-il, mais cette question du rythme s'inscrit à deux niveaux dans le récit: le rythme sonore et le rythme de progression de la foule qui remplit peu à peu la ville, envahissant les tilleuls («Linden »). 
Matin d'ouverture des XI ${ }^{\text {es }}$ Jeux olympiques de l'ère moderne. Pauvre petit Français, baron Pierre de Coubertin, qui rêva d'un «Empire du Matin calme»! Ce qui se passe ici est à peine croyable. Le magma humain a commencé de fluer dans le lit des Avenues, mais cette fois les Schupos automatiques, pareils à des sémaphores synchronisés, ont fait le vide au milieu des «Linden », sur le terre-plein couleur de brique. Là, dès huit heures du matin (l'ouverture des Jeux se fait à 4 heures du soir), circulent les fanfares aux cymbales qui se pulvérisent, et les cliques de tambours et de fifres, puissamment cadencés, qui entraînent la parade des cohortes casquées, couleur d'herbe. Pas de parade sur des airs de « lieds »! Le ciel est plein d'un orage d'avions qui vont et viennent au-dessus de la ville. Et avec eux cette bête d'Apocalypse qu'on nomme le Zeppelin.

Voici de nouveau des tambours, des roulements de tonnerre lointain, la clameur humaine qui monte vers nous et emplit les hautes avenues comme les précipices du bruit des cataractes. Voici des rythmes de cymbaliers qui se précisent, rappelant nos moyens-âges. Des jeunesses brunes, à l'ombre de la croix gammée, chantent des hymnes religieux coupés d'arrêts secs comme des aboiements, et suivis de silence où l'on n'entend plus que le roulement des pas. L'éclat des longs tambours médiévaux, frappés d'une seule main, à la batte, ne cesse de retentir : un, deux, puis trois coups rapides. Voici des trompes à la façon des Scouts. Les Jeunesses hitlériennes défilent. « Hitlerjugend ».

Berlin est une ville de rythme. L'esprit lyrique souffle sur elle et en elle, puissamment. Métropolis.

[...]

L'atmosphère monte de minute en minute. La ville se gonfle comme sous l'action d'un levain, "Unter den Linden", sur le terre-plein, couleur de brique, voici soudain qu'apparaissent les athlètes en costumes d'apparat, dans les uniformes qu'ils se sont choisis : les Grecs luxueux, en jupons, marchent en tête, derrière leur drapeau bleu à croix blanche, les Hindous au turban rose-rose, fripés comme des pétales d'orchidées.

La cohue est de plus en plus énorme : il est impossible de la chiffrer; elle s'écrase maintenant des deux côtés des Linden, sur les trottoirs. Les athlètes passent acclamés et vont se ranger auprès d'un sombre Mausolée érigé au Soldat Inconnu. Là se range, s'aligne à son tour le Comité Olympique dans ses uniformes noirs. Les troupes allemandes, casquées, les marins hypnotiques défilent, au pas de parade et masques crispés, derrière les tambours et les fifres. [nous soulignons]

Le reporter mobilise toutefois une série d'images qui sont loin d'être anodines. Les champs lexicaux choisis confèrent à la ville une atmosphère lourde et inquiétante. Les sons sont ainsi décrits sous le mode de la " percussion "; les couleurs vives, les ombres et les lumières font image. La métaphore de l'orage qui accompagne le survol des avions et celle des chiens (aboiements) qui caractérise les chants des jeunesses hitlériennes soulignent la portée militariste de l'événement. La référence au Soldat Inconnu est d'ailleurs explicite. La foule décrite comme " un magma humain » se dirige pourtant irrémédiablement vers le stade. Mais cette volonté de maitrise des masses est accentuée plus avant dans l'article :

[Les chefs du nouveau Reich] vont parler à cette grande invasion brune qui se fait maintenant sur la place: l'invasion massive et rythmée par les tambours, qui claquent à tous les échos. Invasion des Jeunesses Hitlériennes, jaunes, sur des rythmes de caisses ébranlées. Ils arrivent sur deux larges colonnes, laissant entre eux une voie étroite par où passera tout à l'heure le coureur portant la Torche en feu. Ils arrivent de plus en plus, houle de têtes, têtes blondes, couleur de paille, par les épaules et les nuques rases et par les cheveux au dessus couleur d'épis brûlés et mûr pour la moisson. Couleur de seigle.

Tout à coup, l'immense place est pleine et serrée comme un champ de blé. Pourtant on engrange toujours les têtes, on les entasse. Je n'ai jamais rien vu 


\begin{abstract}
d'humain qui ressemblât autant à un champ de seigle. Les tambourins battent et maintenant la masse oscille, sur place, au rythme de ce bruit sec comme celui de fléaux sur l'aire. Moisson humaine. Les chefs font maintenant pleuvoir, sur cette récolte humaine, la pluie des paroles fécondantes. Et chaque fois après eux, monte le chant, comme signe d'accord. Hymne olympique, qui est allemand, et d'autres lieds. Ils sont là 150 mille peut-être qui chantent, à voix de tête et à voix muées comme des enfants qui marchent à la mort.

Soudain, derrière l'auteur, sortent les drapeaux : drapeaux rouges, en file serrée, puis, derrière, des drapeaux noirs, macabres, avec leurs insignes blancs. Il me semble qu'il y a toujours quelque chose de macabre au fond des grandes cérémonies allemandes. Quelque chose de théâtral et de funèbre à la fois. Cet hymne olympique, composé par un Allemand, est nostalgique. Le ciel est gris... Il tombe une fine pluie. Il me semble, dans ces chants monotones et puissants comme des houles, respirer un goût de mort. Il ne fait point joyeux. Le sens profond de cette cérémonie, c'est non point la joie mais la passion. Il fait funèbre sur cette grisaille, au milieu de ces drapeaux couleur de sang et couleur de mort parmi cette jeunesse aux cheveux de seigle, à l'ordre de ces chefs vêtus comme des hommes de camps. [nous soulignons]
\end{abstract}

S'appuyant habilement sur la référence à la blondeur aryenne, Werrie file la métaphore du «champ de blé » pour souligner la portée propagandiste de l'événement. Le glissement qu'il opère ensuite vers le champ lexical de "la mort» ("macabre», "funèbre »), indique une conscience des enjeux militaristes qui sous-tendent l'événement. La conclusion de l'article est d'ailleurs explicite. Le sens profond que le reporter entend donner à l'événement - la passion - se joue, par sa polysémie (sens religieux, théâtral, émotionnel), des effets idéologiques de la référence antique pour renvoyer l'événement à une époque autrement référencée : le Moyen Âge ${ }^{28}$.

Si cet article de Werrie laisse à penser que le reportage a pu être le lieu d'expression d'une conscience antifasciste, la lecture du reportage dans son ensemble (soit une dizaine d'articles pour Le Vingtième siècle) témoigne toutefois d'une certaine ambiguïté. L'article du 17 août lui-même, qui n'occupe que trois colonnes sur sept, fait face à un autre article de Werrie, intitulé "L'impérialisme nègre. Les exploits des athlètes noirs ». Plusieurs titres d'articles signés par Werrie font explicitement référence à la question raciale: «couleur du premier jour : beaucoup de Noir et du Jaune $»^{29}$ ou encore : «le troisième jour : il fait toujours "noir" $\aleph^{30}$. Dans le contenu même de ses reportages, les athlètes sont systématiquement envisagés selon leur couleur de peau ou leur "race»: "toutes les nations civilisées, dit-on : c'est un euphémisme. [...] toutes les races, demi-races et quart de races. Toutes les couleurs de peau. Tout le dégradé de l'épiderme humain. $»^{31}$ ou encore : «Que voulez-vous ? Tous ces noirs, demi-noirs, ou bruns ou rouges ou jaunes, [...] sont plus proches que nous du Primitif et donc plus adroits à toutes ces choses! $! »^{32}$ Les propos que Werrie tient à l'encontre de l'athlète noir américain Jesse Owens sont tout aussi explicites : «il est quand même assez drôle de penser que l'héritage de la Grèce se retrouve en ce Nègre [Jesse Owens] à Berlin ${ }^{33}$. »

De Jesse Owens, les reporters du Soir et de La Dernière Heure ne parleront que pour citer ses records olympiques. Aucun des deux journaux ne fera mention de l'incident survenu lorsque l'athlète devient champion olympique de saut en longueur, battant l'allemand Lutz Long et qu'Hitler quitte le stade. Cet événement qui aurait pu permettre de critiquer le concept de race aryenne est passé sous silence.

37 L'ambiguïté des reporters à l'égard de l'idéologie sous-jacente aux JO se situe donc au carrefour du dit et du non-dit. S'y tisse également ce qu'on pourrait qualifier de 
«spécificité belge » dans l'attitude des reporters envoyés à Berlin. Nous commencerons notre conclusion par ce point.

\section{Le dit et le non-dit}

La presse belge participe peu à la surenchère nationaliste dont les Jeux ont été (et sont toujours) le prétexte. L'absence de victoire explique évidemment cette modestie. Mais deux autres facteurs s'y ajoutent. D'une part, la discrétion du gouvernement belge, que nous avons déjà signalée, a sans doute été interprétée comme une incitation à adopter la même attitude. Mais, d'autre part, il est probable que le contexte politique national a joué aussi son rôle. Du 3 juin 1936 au 24 novembre de l'année suivante, le gouvernement Van Zeeland II est un gouvernement d'union nationale, rassemblant socialistes, catholiques et libéraux unis contre la vague montante du parti rexiste de Léon Degrelle. Issu du monde catholique, le leader populiste est «lâché » par la hiérarchie de l'Église le 9 avril 1937, lorsque le cardinal Van Roey, primat de Belgique, condamne le vote rexiste. Pendant l'été 1936, la grande presse catholique était donc loin d'être ralliée au rexisme, même si elle partageait son anticommunisme radical. Soutenir l'Allemagne nazie sans autre forme de procès aurait été certainement interprété, en Belgique, comme un soutien à Degrelle.

39 Ce contexte permet de comprendre l'ambiguïté idéologique des articles de Paul Werrie. À la fois admiratif de l'effort collectif et méfiant à l'égard de la militarisation de l'Allemagne, l'homme n'a manifestement pas encore entamé l'évolution qui le conduira à la collaboration avec l'Occupant. Il écrit également pour des journaux qui n'abandonneront pas le giron idéologique traditionnel de l'Église. Le savant dosage d'admiration et de réserves dont il fait preuve dans ses articles s'aligne très précisément sur les indécisions de ses commanditaires.

40 En un second volet, notre enquête suggère par ailleurs quelques conclusions portant sur la poétique du reportage.

Essentiellement construite à partir de l'exemple des grands reporters de l'entre-deuxguerres (Londres, Viollis, Béraud, Kessel, etc.), la poétique du grand reportage a su définir le modèle journalistico-littéraire de leurs interventions. Entre la littéralité de la chose vue et la littérarité de la chose écrite, les grands reporters nouent un pacte avec leur lecteur. Ils s'engagent à dire le vrai d'une actualité, en attestant de leur présence testimoniale énoncée à la première personne. Leur compétence professionnelle, souvent mise en scène dans le corps même du texte ou par l'intermédiaire de photographies, établit à la fois un regard "autorisé " sur les faits et la capacité de les analyser, voire à prédire leur évolution ${ }^{34}$. Cette personnalisation du regard différencie leur écriture de celle des agences de presse, dont la fiabilité s'inscrit dans une rhétorique de l'évidence et de la factualité régie par l'anonymat énonciatif.

Dans le cas belge, où seuls trois reporters ont effectivement pu être identifiés, l'importance de la signature d'un journaliste-vedette est l'exception et non la règle. La presse quotidienne apparaît ainsi comme le lieu d'une énonciation fondée sur un contrat légèrement différent, conditionné par l'orientation du support de presse. Elle donne la parole à des énonciateurs subjectifs quasi anonymes. Ceux-ci relaient tout à la fois un discours sur l'événement et l'horizon d'attente du lectorat particulier de leur journal. Comme il aurait été impensable que Werrie clame un enthousiasme sans nuance pour l'Allemagne nazie en écrivant dans un grand quotidien catholique (quels qu'aient été ses 
sentiments personnels), il est impossible que le reporter n'anticipe pas les choix de ses commanditaires. Dès lors, il se trouve face à un "espace du dicible» contraint non seulement par ce qu'il voit mais par ce qu'il sait et a intériorisé de la publication de son reportage. Il nous faut donc réviser l'idée un peu romantique d'un énonciateur libre de ses choix et préservé des réalités par la notoriété de sa signature.

Un autre type de contrainte, particulièrement perverse dans le cas qui nous occupe, tient à la nature même des Jeux. Nous avons compris que tout avait été organisé pour produire une certaine impression, une image favorable de l'Allemagne, de son chef et de son idéologie. Que devient dès lors la poétique de la «chose vue » dans ce cas? Un reporter qui se bornerait à décrire ce qu'il voit se condamnerait à ne saisir que l'apparence spécieuse d'un trompe-l'œil de propagande. Dire la vérité sur les Jeux consisterait à parler de ce qu'ils dissimulent. Le contrat de vérité, en l'occurrence, est exactement l'inverse de celui qu'on attend: le journaliste devrait pouvoir témoigner de ce qu'il ne peut pas voir, dire le vrai du faux en quelque sorte. On comprend l'embarras des reporters, dès lors qu'ils ont été envoyés à Berlin pour un temps limité, avec la mission de traiter des Jeux pour lesquels vaut leur accréditation et encadrés par la très efficace organisation allemande.

Comme c'est souvent le cas dans un contexte éditorial contraignant, une stratégie du double discours se met dès lors spontanément en place. Elle porte autant sur le contexte d'énonciation que sur le contexte des épreuves olympiques. Revenons une dernière fois sur l'article cité de Paul Werrie : l'incipit insiste sur le fait qu'il envoie son reportage " après coup ", qu'il doit " développer » son impression et que " la question d'actualité ne joue guère ». Ces précisions temporelles et la métaphore photographique sont autant de dénis de l'illusion du direct que le reportage est censé construire. Elles impliquent qu'il faudra laisser du temps au temps pour qu'une réflexion s'installe, que la vue des événements risque de n'être qu'un "cliché ". Plusieurs journaux gèrent cette distance nécessaire par un recadrage explicite. Avant, pendant, ou le plus souvent après les événements purement sportifs, ils reviennent sur ce qui fait problème, comme La Libre Belgique du 10 juillet, qui mentionne la question de l'antisémitisme ou l'article de V. de C., «Berlin camouflé par l'olympiade. Du $1^{\mathrm{er}}$ au 16 août, la capitale allemande a vécu dans l'artificiel » (La Meuse, 21 août 1936, p. 5). La même distance s'observe aussi dans le corps même des reportages par l'usage rhétorique de l'ironie. On appréciera dès lors la subtilité de Gérard de Lantsheere lorsqu'il écrit: «la ville est sillonnée par les voitures d'étatmajor, les caissons camouflés et les miliciens de guerre civile qui attendent sans impatience la démobilisation. À la première inspiration, cette atmosphère est charmante " (La Nation belge, 2 août 1936) : le mot "charmant ", typique d'un éthos aristocratique distancé, prend ici toute sa valeur. De même, chez Pierre Gosset, le commentaire météorologique vaut comme une critique indirecte du culte de la personnalité du Fürher : « la présence journalière du chancelier Hitler devait sembler une suffisante assurance contre la pluie pour qu'on ne s'en occupe pas davantage. Vous souriez? Vous avez tort : c'est un journaliste allemand qui nous disait très sérieusement, avec une conviction presque désarmante que, lorsqu'Hitler parlait, le soleil faisait son apparition. « (L'Indépendance belge, 7 août 1936).

L'ironie, on le sait, pose toujours le problème de son interprétation ${ }^{35}$. Qui peut la décoder? Quel sens lui donner? Elle peut n'être qu'un indice de l'éthos du locuteur sans rien livrer de ses convictions profondes, comme c'est le cas dans l'exemple cité de de Lantsheere. D'autres formes de la distance critique posent ainsi d'insolubles problèmes. 
Plusieurs journalistes pratiquent l'allusion. Lorsque La Dernière Heure, journal libéral peu favorable au nazisme, écrit que «le ciel reste gris, la température plutôt froide » en conclusion à un article intitulé "Le chancelier Hitler a reçu les membres du comité olympique international... » (G. et al., La Dernière Heure, 2 août 1936), on serait tenté de lire une métaphorisation critique des relations entre le régime allemand et nombre de membres du CIO. Mais ne surinterprétons-nous pas cette allusion? La question devient lancinante quand on compare le contenu des articles avec l'ensemble des initiatives du Reich que nous avons rappelées plus haut. Peut-on interpréter comme des omissions volontaires le peu d'informations données sur la cérémonie de clôture, sur des cérémonies annexes et notamment théâtrales, sur l'hommage aux morts de la Grande Guerre, qui n'apparaissent presque pas dans la presse belge alors que la presse canadienne en rend compte, sur la place des militaires dans l'athlétisme allemand, sur les réactions nationalistes du public? Ne pas évoquer un fait est-il ignorance, manque de place ou choix politique? Ces questions demeurent sans réponse, bien évidemment, mais les poser donne la mesure de l'intérêt de l'enquête.

\section{NOTES}

1. La citation du titre est de Paul Gosset dans La Vie sportive (6 août 1936, p. 3).

2. Ces questions ont guidé le séminaire que nous avons animé au printemps 2014, et dont nous présentons ici les résultats. Ont participé à ce séminaire les étudiants de BA3: Marie-Sophie Cariat, Sarah Devigne, Florent Leduc, Valentine Lefevre, Lorraine Mathon; ainsi que Fanny Urbanowiez.

3. Sombreffe Jean-Christian, « La participation de la Belgique aux Jeux olympiques de Berlin en 1936 », Revue belge d'histoire contemporaine, vol. 3-4, 1998, p. 405-443. Signalons l'existence d'un « reportage » inédit très intéressant rédigé par le jeune Raymond Screvens, membre de l'équipe de handball, qui raconte "ses" jeux. (Manuscrit CEGES AB 2541). Ce témoignage confirme la préparation approximative de l'équipe belge, mais également la présence constante des drapeaux nazis et la dimension militaire des jeux.

4. Cette poétique a été en particulier décrite par Myriam Boucharenc (Boucharenc Myriam, L'écrivain-reporter au cœur des années trente, Villeneuve d'Ascq, Presses universitaires du Septentrion, 2004 ; Boucharenc Myriam, "Choses vues, choses lues : le reportage à l'épreuve de l'intertexte ", Cahiers de Narratologie [En ligne], 13 | 2006, mis en ligne le 01 septembre 2006. URL : http://narratologie.revues.org/320). Voir aussi l'article que nous consacrons à la méthodologie de l'enquête.

5. Le Matin ; La Métropole; La Meuse, Le Journal de Charleroi et La Gazette de Charleroi ; Cassandre et Le Vingtième siècle; L'Indépendance belge; Le Soir, La Dernière Heure ; La Libre Belgique, La Nation belge.

6. Nous avons particulièrement utilisé les travaux suivants : Bolz Daphné, Les années totalitaires, Paris, CNRS éditions, 2008 ; Brohm Jean-Marie, 1936, Les jeux olympiques de Berlin, Bruxelles, André Versaille, 2008; Guilbert Laure, Danser avec le IIIe Reich, les danseurs modernes et le nazisme, Bruxelles, Complexe, 2000 ; Sombreffe Jean-Christian , op. cit., p. 3-4.

7. Et en particulier le travail des architectes Albert Speer (1905-1981), architecte en chef du Parti nazi depuis 1934, et Werner Julius March (1894-1976). 
8. Le théâtre sera bâti par Werner Marc, d'après les plans de Konrad Robert Heidenreich, spécialiste des théâtres de verdure qu'il avait étudiés en Italie.

9. Les plans du stade dessinés par Werner Marc ayant été jugés trop modernes par Hitler, Speer en modifia le dessin en ajoutant à l'édifice une façade de pierre.

10. Voir : http://www.youtube.com/watch?v=yn7i6G0-cJs

11. Olympia 1936 und die Leibesübungen im Nazionalsozialistischen staat. Herausgegeben von Friedrich Mildner, Buchvertrieb Olympiade, 1936, Berlin, 1936, 2 vol. Cet album de propagande, sur le sport en Allemagne, montre bien les liens entre le régime, la SS et les valeurs sportives...

12. Georges Blun, «Après les Jeux olympiques de Berlin. Victoire sportive ou victoire de régime. Un problème capital pour la civilisation ", La Nation belge, 21 août mais rédigé à "Berlin, 17 août ».

13. Rappelons que le comte de Baillet-Latour a eu un fils décédé dans les rangs de l'armée anglaise en 1942. Son neveu, Alfred de Baillet Latour (1901-1980) développe la brasserie Stella Artois, où il entre en 1936 et qu'il dirige de 1947 à 1980. Il en a fait un groupe d'importance mondiale (Inbev). La fondation Baillet-Latour qu'il a créée finance aujourd'hui des recherches sur l'olympisme ainsi qu'une chaire sur l'histoire du sport à l'Université de Louvain ( http:// sites.uclouvain.be/chaire-olympique/ ).

14. D'après la liste des journalistes accrédités conservée dans les archives du CIO. Voici la liste complète de ces journalistes, dont on constatera qu'elle ne correspond pas exactement aux signatures des articles que nous citons, sans doute en raison de la réécriture de certaines correspondances : Frits Ardouillie (Le Matin d'Anvers), Victor Boin (envoyé libre), Norbert Diagre ( La Dernière Heure), Edouard Duchâteau (Liège), Durhean (La Meuse), Marcel Fluche (La Vie sportive), Ernest Gaillez (Gand), Ferdinand Germain (Bruxelles), Léon Gerson (Le Journal de Malmédy), Oscar Van Godtsenhoven (Les Sports), Pierre Gosset (L'Indépendance belge), Aloïs Janssens (La Métropole), Emile Kneipe (Bruxelles), René Lang (Le Journal de Malmédy), John Langenus (Het Handelsblad, Antwerpen), Gérard de Lantsheere (La Nation belge), Albert Mestag (Bruxelles), Julien Monteyne ( Le Peuple), Prosper de Sahuguet (La Dernière Heure), Auguste van Schoore (Les Sports), Arthur Vandenbak (Het Laatste Nieuws), François Verdicht (La Dernière Heure), Léo Vermaesen (Sportwereld ), Jules Vlerick (La Dernière Heure), Paul Werrie (Le Vingtième Siècle).

15. Gérard de Lantsheere (1906-1972), dit Gerdel, correspondant de La Nation belge à Paris, puis rédacteur en chef de ce quotidien après la Libération, devint correspondant du Parisien libéré à Bruxelles en 1956 (Catherine Lanneau, L'Inconnue française: la France et les Belges francophones, 1944-1945, Bruxelles, PIE Peter Lang, 2008, p. 97).

16. Annuaires de la presse sportive belge, Bruxelles, Association Professionnelle Belge des Journalistes Sportifs, 1933 (p. 91) et 1936 (p. 115).

17. Sur cette question, nous renvoyons aux travaux d'Emmanuël Souchier sur l'« énonciation éditoriale » et à ceux de Marie-Ève Thérenty sur la notion de " poétique historique du support » (Souchier Emmanuël, « L'image du texte pour une théorie de l'énonciation éditoriale », Les cahiers de médiologie, 1998/2 N 6, p. 137-145. En ligne: http://www.cairn.info/revue-les-cahiers-demediologie-1998-2-page-137.htm ; Souchier Emmanuël (dir.), «L'énonciation éditoriale en question", numéro spécial de Communication \& langages, $n^{\circ} 154$, décembre 2007, p. 23-121 et 135-138; Souchier Emmanuël « Formes et pouvoirs de l'énonciation éditoriale », Communication et langages. $\mathrm{N}^{\circ} 154,2007$, pp. 23-38. En ligne :http://www.persee.fr/web/revues/home/prescript/ article/colan_0336-1500_2007_num_154_1_4688; Thérenty Marie-Ève, La littérature au quotidien. Poétiques journalistiques au XIXe siècle, Paris, Seuil, coll. « Poétique », 2007 ; Thérenty Marie-Ève, «Pour une poétique historique du support », Romantisme, 2009/1 n 143, p. 109-115. En ligne : http://www.cairn.info/revue-romantisme-2009-1-page-109.htm ; Thérenty Marie-Ève, « Poétique historique du support et énonciation éditoriale : la case feuilleton au XIXe siècle », Communication \& langages, 2010, pp 3-19. En ligne : http://necplus.eu/abstract_S0336150010014018) 
18. Souchier Emmanuël, «L'image du texte pour une théorie de l'énonciation éditoriale », op. cit., p. 144.

19. C'est le cas notamment de La Gazette, de L'Etoile belge ou encore du quotidien rexiste Le Pays réel.

20. Marie-Ève Thérenty a en effet très bien montré que « la matrice journalistique », en tant que principe d'écriture, se fonde sur quatre règles: la périodicité, l'actualité, l'effet-rubrique et la collectivité, largement induite par la polyphonie du journal (Thérenty Marie-Ève, La Littérature au quotidien : poétiques journalistiques au XIXe siècle, Paris, Seuil, 2007).

21. Gourou Pierre, «Le port d'Anvers ", Annales de géographie, 1942, t. 51, n²86, p.150, consulté le 22 avril 2014.

22. Lambrette Denise, Le journal « La Meuse ». 1855-1955, Louvain-Paris, Nauwelaerts, 1969, p. 68.

23. La Métropole, le 3 août 1936.

24. Ibid.

25. Pierre Gosset, « Images des Jeux... », L'Indépendance Belge, 6 août 1936, p. 10.

26. «Berlin, tour de Babel », La Vie Sportive, 6 août 1936, p.1. On retrouve une poétique similaire dans un article du Courrier de l'Escaut daté du 2 août 1936: «Plus grand que le Colisée, le Stade olympique contiendra 115000 spectateurs!»

27. Werrie Paul, «Un étrange spectacle à Berlin. 'Heilige flamme!' s'écria M. Goebbels », Le Vingtième siècle, 7 août 1937, p. 4.

28. On notera d'ailleurs la mention, à deux reprises, dans la première partie de l'article de termes renvoyant à cette époque (« moyens âges » et « médiévaux »).

29. Le Vingtième siècle, 4 août 1936, p.2.

30. Ibid., 5 août 1936, p.4.

31. Ibid., 4 août 1936, p.1.

32. Ibid., 2 août 1936, p.1.

33. Cassandre, 13 Août 1936, «L'impérialisme nègre à Berlin », p.10.

34. Rappelons également que le grand reporter occupe une place très limitée dans l'institution de la presse : sur quelque trois mille journalistes en activité en France, une soixantaine seulement revendiquent ce statut, et sur ce nombre, un dixième à peu près sont encore connus de nos jours.

35. Pierre Schoentjes, Poétique de l'ironie, Paris, coll. « Points/Essais-Inédits », 2001.

\section{ABSTRACTS}

Bien représentés parmi les reporters étrangers accrédités en Allemagne, les journalistes belges ont rendu compte des Jeux sans trop céder à la propagande nazie. Omniprésente toutefois sur les terrains sportifs comme le rappelle l'article, celle-ci transparait dans les notations d'atmosphère et dans les questions que posent les articles. Par profession attentif à la scénographie, que son écriture va traduire, le reporter ne peut en effet rester indifférent à un spectacle dont il est partie prenante, objet autant que sujet. Pour autant, il n'est pas toujours aisé de décoder sa position sans risquer l'anachronisme. C'est à cet exercice difficile que ce consacre cet article, issu d'un séminaire de troisième année en BA en Langues et Littératures françaises et romanes de l'ULB. 


\section{INDEX}

Mots-clés: presse belge, ironie, photographie, reportage, envoyés spéciaux, jeux olympiques 1936, Belgique

\section{AUTHORS}

\section{PAUL ARON}

Paul Aron est directeur de recherches au FNRS et professeur à l'ULB. Il est l'auteur de nombreux travaux en sociologie et en histoire de la littérature de langue française.

Il a publié avec Vanessa Gemis :

"Le littéraire en régime journalistique », ss la dir. de Paul Aron et Vanessa Gémis, Contextes, 11, 2012 http://contextes.revues.org/5296

Ingrid Mayeur, Vanessa Gemis, et Paul Aron, « Journalisme et littérature en Belgique francophone : bilan et perspectives », Médias 19 [En ligne], Nouveaux bilans, Publications, Micheline Cambron et Stéphanie Danaux (dir.), La recherche sur la presse : nouveaux bilans nationaux et internationaux, mis à jour le :06/12/2013, URL : http://www.medias19.org/ index.php?id=15540.

\section{VANESSA GEMIS}

Vanessa Gemis a été chargée de recherches au FNRS ; elle est actuellement en charge de EU liaison office (Cellule Europe) à l'ULB. Elle a réalisé une thèse de doctorat portant sur Femmes de lettres belges (1880-1940). Identités et représentations collectives (ULB, 2009). Elle est secrétaire de rédaction de la revue Sextant.

Elle a publié avec Paul Aron :

« Le littéraire en régime journalistique », ss la dir. de Paul Aron et Vanessa Gémis, Contextes, 11, 2012 http://contextes.revues.org/5296

Ingrid Mayeur, Vanessa Gemis, et Paul Aron, « Journalisme et littérature en Belgique francophone : bilan et perspectives », Médias 19 [En ligne], Nouveaux bilans, Publications, Micheline Cambron et Stéphanie Danaux (dir.), La recherche sur la presse : nouveaux bilans nationaux et internationaux, mis à jour le :06/12/2013, URL : http://www.medias19.org/ index.php?id=15540.

Philixte, Université libre de Bruxelles 